\title{
Different responses of the halophyte Carex pumila to salt stress
}

\author{
S.W. WANG ${ }^{1,2}$, F.F. XU ${ }^{3}$, L.J. GUO ${ }^{3}$, T.T. HE ${ }^{1,2}$, X.L. LI $^{5}$, L. YUAN ${ }^{1}$, Q.F. WANG ${ }^{1,4}$, and H.T. LIU ${ }^{1 *}$ \\ Key Laboratory of Plant Germplasm Enhancement and Specialty Agriculture, Wuhan Botanical Garden, \\ Chinese Academy of Sciences, Wuhan, Hubei 430074, P.R. China ${ }^{1}$ \\ University of Chinese Academy of Sciences, Beijing 100049, P.R. China ${ }^{2}$ \\ Collage of Life Sciences, Shangrao Normal University, Shangrao, Jiangxi 334001, P.R. China ${ }^{3}$ \\ Sino-Africa Joint Research Center, Chinese Academy of Sciences, Wuhan, Hubei 430074, P.R. China ${ }^{4}$ \\ The Institute of Advanced Studies in Coastal Ecology, Ludong University, Yantai 264000, P.R. China
}

\begin{abstract}
Salt stress is one of the most important stresses that affect coastal vegetation. A halophyte Carex pumila plays a crucial role in the maintenance of fragile ecosystems in coastal areas. Thus, understanding the mechanism of $C$. pumila responses to salt stress is a prerequisite for the conservation and utilization of this species. After treatment with 200, 300, 400, 500 mM $\mathrm{NaCl}$ for $60 \mathrm{~h}$, C. pumila leaves displayed a decline in the relative water content and an increase in salt injury index. Osmolyte accumulation, as a function of osmotic adjustment, and antioxidant enzyme activities were maintained under salinity, even at a high $\mathrm{NaCl}$ concentration. High $\mathrm{NaCl}$ concentrations severely affected the photosystem II, the JIP-test indicated a significant decrease in performance indexes and quantum efficiencies and an increase in phenomenological fluxes. Metabolic analyses showed the changes of 39 metabolites, including 16 kinds of organic acids, 9 kinds of amino acids, 9 kinds of sugars, 3 kinds of sugar alcohols, and 2 amines. The identified metabolites were mainly involved in the glycolysis, pentose phosphate pathway, and tricarboxylic acids cycle.
\end{abstract}

Additional key words: antioxidant enzymes, chlorophyll $a$ fluorescence, metabolites, $\mathrm{NaCl}$, osmotic adjustment.

\section{Introduction}

The coastal zone has its special vegetation ecosystem that plays an important role in coastal soil and water conservation and most beach plants act as "bioshields" for beach protection, inhibition of coastal erosion, and sandstorms reduction (Dahdouh-Guebas and Koedam 2006). However, coastal beaches are narrow and isolated fragmented habitats that limit the size of plant populations and allow plant populations to be naturally constrained in gene exchange and survival (Hämmerli and Reusch 2003, Feagin et al. 2010). Coastal habitats are fragile, and, currently, the coastal beach plants are increasingly suffering from serious human encroachment (Rodgers et al. 2009, Iwasato and Nagamatsu 2018) and affected by various abiotic stresses including salt stress.

Many coastal halophytes have formed different salt tolerance mechanisms during long-term adaptive evolution. The effects of salinity on plants include reduced growth, ion toxicity, osmotic stress, mineral deficiencies, nutritional disorder, photosynthetic imbalance, and combinations of these effects (Evelin et al. 2009, Jenkins et al. 2010, D'Amelia et al. 2018, Morton et al. 2019). Salt stress causes oxidative damage by excessive production of reactive oxygen species (Zheng et al.2009, Zhu et al. 2019), and superoxide dismutase (SOD) is a major scavenger of $\mathrm{O}^{2-}$, as it catalyzes the dismutation of superoxide radical anions into $\mathrm{O}_{2}$ and $\mathrm{H}_{2} \mathrm{O}_{2}$ (Scandalios 1993). The produced $\mathrm{H}_{2} \mathrm{O}_{2}$ is then dismutated into $\mathrm{H}_{2} \mathrm{O}$ and $\mathrm{O}_{2}$ by CAT and POD (Parida et al. 2004, Garg and Manchanda 2009). Salt stress also affects plant photosynthesis, including the function of chloropplasts (Allakhverdiev et al. 2000, Zhang et al. 2018). Metabolomics, as the end products of cellular regulatory processes, are crucial functional genomics tools for understanding plant response to salt stress (Lu et al. 2002, D'Amelia et al. 2018). Plants regulate the content of multiple metabolites to protect them from the detrimental effects of salinity (Kumari et al. 2015). Many studies have revealed that small soluble metabolites, including amino acids, such as proline, pipecolic acid, sugars,

Submitted 28 February 2020, last revision 29 April 2020, accepted 18 May 2020.

Abbreviations: CAT - catalase; DI - injury index; EL - electrolyte leakage; GC-MS - gas chromatography - mass spectrometry; MDA - malondialdehyde; OJIP - chlorophyll $a$ fluorescence induction transient; POD - peroxidase; PS II - photosystem II ; RWC - relative water content; SOD - superoxide dismutase; TCA - tricarboxylic acid; CK - control treatment.

Acknowledgements: This research was funded by the Sino-Africa Joint Research Center, CAS, China (Y323771W07 and SAJC201322) and the National Natural Science Foundation of China (31860200). The first three authors contributed equally to this work.

* Corresponding author; e-mail: lhongtao@wbgcas.cn 
such as glucose, fructose, sucrose, trehalose, raffinose, and fructans, sugar alcohols, such as sorbitol, mannitol, glycerol, inositol, and methylated inositols, polyamines, such as putrescine, spermidine, and spermine participate in plants response to abiotic stresses (Mansour 2000, Stitt and Hurry 2002, Chen and Murata 2008, Ferchichi et al. 2018).

Carex pumila, (commonly known as draft sedge) is a widely distributed herb that is adapted to the coastal beach habitats (Burgess 1984). C. pumila is widely distributed for example in New Zealand, Australia, Chile, China, Japan, and Korea. As a clonal plant, C. pumila has large underground rhizome system, which plays an important role in the protection of coastal sands and soils. Unfortunately, because of the special nature of coastal habitats as well as other abiotic stress effects, the $C$. pumila population has gradually declined in China's coastal regions and has even disappeared in some regions. Sand dune vegetation has often been considered to be non-halophytic (Rozema et al. 1983), this is because sand salinity of the coastal zone is normally around $1 \%$ (Hope-Simpson 1955) and sand is a highly porous medium which allows rapid salt leaching by rainwater. However, rain leaching is less effective in dry summer weather and in arid regions. Salinity may also be high in dune hollows, of up to $3-5 \% \mathrm{NaCl}$ (Sykes and Wilson 1989). As a halophyte, C. pumila has been previously reported by Sykes and Wilson (1989) to survive up to $2 \%$ salt for a prolonged period. However, the physiological and metabolic mechanisms of salt tolerance in C. pumila have not been reported. Thus, understanding the mechanism of $C$. pumila response to salt stress is important for the conservation and utilization of $C$. pumila and for breeding of salt-tolerant crops.

This study was designed to investigate the mechanism of $C$. pumila response to salt stress. We particularly focused on the modulations of antioxidant enzymes activities, photosynthesis, and metabolisms. This study provides some insights into the possible mechanisms of salt tolerance ability in C. pumila.

\section{Materials and methods}

Plants and growth conditions: The $C$. pumila used in this study was collected from wild fields of Taohua Island, Zhejiang Province, China (latitude 29 48'59"N and longitude $\left.122^{\circ} 17^{\prime} 43^{\prime \prime} \mathrm{E}\right)$. The average salinity of habitat is about $1.231 \%$, and the salt content of seawater is about $2.4 \%$. About $15 \mathrm{~cm}$ rhizome were reserved and planted in triangular bottle (150 $\mathrm{cm}^{3}$ and wrapped in foil) with Hoagland's nutrient (Hoagland and Arnon 1950, Shahverdi et al. 2019) in incubator (CIMO-GZX-250BSH-III, Shanghai, China), which was set at a temperature of $26^{\circ} \mathrm{C}$, an irradiance of $\sim 250 \mu \mathrm{mol}$ (photons) $\mathrm{m}^{-2} \mathrm{~s}^{-1}$, a $16-\mathrm{h}$ photoperiod, and a $\sim 60 \%$ relative humidity. The nutrient solution was replaced every $5 \mathrm{~d}$ and aerated 3 times per day for $30 \mathrm{~min}$. One-month-old C. pumila healthy plants of a similar size were used for the next salt treatments.
Salt treatments and experimental design: The plants were subjected to five salinity levels: 0 (control), 200, 300, 400 , and $500 \mathrm{mM} \mathrm{NaCl}$. Salinity was increased every $8 \mathrm{~h}$ by increments of $100 \mathrm{mM} \mathrm{NaCl}$ until final salinity was achieved. After that, plants were exposed to the final $\mathrm{NaCl}$ concentrations for $60 \mathrm{~h}$. During the period of salt exposure, the plants were maintained in the incubator under the same environmental conditions as mentioned above. At the end of the experiment, all leaves were sampled from the plants and then immediately frozen in liquid nitrogen and stored at $-80{ }^{\circ} \mathrm{C}$ for further analyses. The salt treatments were arranged in a randomized complete block design with three replicates.

Salt injury (DI) index was scored for visible symptoms on a 1 - 4 scale as follows: 1 - no injury; 2 - browning on shoot-tips and leaf edges or slightly curling or drooping; 3 - serious leaves curling or drooping or/and wilting; 4 - dead. Following this scale, salt injury index (DI) was calculated according to the following formula: DI $=\sum(n i \times i) / N$, where ni is the number of explants receiving the mark " $\mathrm{i}$ " (from 1 to 4 ) and $\mathrm{N}$ is the total number of explants in each $\mathrm{NaCl}$ concentration (Sivritepe et al. 2008).

Quantification of electrolyte leakage: The relative electrolyte leakage (EL) was expressed as the ratio of initial conductivity to the conductivity after boiling and measured by a conductivity meter (Mettler Toledo-FE30Plus, Shanghai, China). About $0.1 \mathrm{~g}$ of leaves was washed three times with deionized water and cut to about $0.5 \mathrm{~cm}$ long fragments. The fragments were transferred into a centrifuge tube $\left(50 \mathrm{~cm}^{3}\right)$ which was filled with $15 \mathrm{~cm}^{3}$ of deionized water, and then the initial conductivity (CA) was measured after being shaken for $24 \mathrm{~h}$ at room temperature. The samples were then heated to $95{ }^{\circ} \mathrm{C}$ for $30 \mathrm{~min}$, and total conductivity (CB) of the bathing solution was then measured after cooling. Electrolyte leakage was calculated from the following equation: $\mathrm{EL}[\%]=(\mathrm{CA} / \mathrm{CB}) \times 100$.

Relative water content: The surface of the leaves was quickly washed with deionized water, the fresh mass (FM) was measured immediately and the dry mass (DM) was weighed after drying at $80{ }^{\circ} \mathrm{C}$ for $15 \mathrm{~h}$. Relative water content (RWC) was calculated from an equation: $\mathrm{RWC}[\%]=(\mathrm{FW}-\mathrm{DW}) / \mathrm{FM} \times 100$.

Malondialdehyde content was determined by the thiobarbituric acid (TBA) method according to Liu et al. (2016). About $1 \mathrm{~cm}^{3}$ of crude enzyme solution was added into $2 \mathrm{~cm}^{3}$ of malondialdehyde (MDA) reaction buffer, which included $0.5 \%(\mathrm{v} / \mathrm{v})$ TBA and $20 \%(\mathrm{v} / \mathrm{v})$ trichloroacetic acid. The mixture was heated at $95{ }^{\circ} \mathrm{C}$ for $30 \mathrm{~min}$ and then cooled to room temperature before being centrifuged at $12000 \mathrm{~g}$ and $20{ }^{\circ} \mathrm{C}$ for $10 \mathrm{~min}$. The absorbance (A) of the supernatant at 532 and $600 \mathrm{~nm}$ was measured using a spectrophotometer (TU-1810, Beijing, China). The MDA content was calculated as $\left[\left(\mathrm{A}_{532}-\mathrm{A}_{600}\right)\right.$ $\times \mathrm{L})] / 1 \times \epsilon \times \mathrm{FM}$, where $\mathrm{L}$ was the volume of the extract solution; 1 indicates the thickness of the cuvettes; $\epsilon$ was the coefficient of absorbance of $155 \mathrm{mM}^{-1} \mathrm{~cm}^{-1}$. 
Enzyme extraction and activities: To extract crude enzymes, about $0.3 \mathrm{~g}$ of leaves were ground to a fine powder in liquid nitrogen and then mixed with $4 \mathrm{~cm}^{3}$ of pre-cooled $150 \mathrm{mM}$ sodium phosphate buffer ( $\mathrm{pH}$ 7.0). The homogenate was transferred to $10-\mathrm{cm}^{3}$ centrifuge tube for centrifugation $\left(12000 \mathrm{~g}, 4^{\circ} \mathrm{C}, 20 \mathrm{~min}\right)$. The supernatant was collected for subsequent assays.

The superoxide dismutase (SOD; EC 1.15.1.1) activity was measured according to the inhibition of photochemical reduction of nitroblue tetrazolium (NBT) (Fan et al. 2014). The reaction mixture $\left(3 \mathrm{~cm}^{3}\right)$ contained $2.2 \mathrm{~cm}^{3}$ of phosphate buffer (50 mM, pH 7.8), $0.1 \mathrm{~cm}^{3}$ of $3 \mu \mathrm{M}$ EDTA-Na, $0.2 \mathrm{~cm}^{3}$ of $195 \mathrm{mM}$ methionine (MET), $0.2 \mathrm{~cm}^{3}$ of $1.125 \mathrm{mM}$ NBT, $0.2 \mathrm{~cm}^{3}$ of $0.06 \mathrm{mM}$ riboflavin, and $0.1 \mathrm{~cm}^{3}$ of enzyme extract. The reaction mixture was kept $30 \mathrm{~cm}$ below the light source for $60 \mathrm{~min}$. All reactants without NBT which served as light blank (CK0) were kept along with samples. The reaction mixture without enzyme extract incubated in the dark served as a dark blank (CKmax). The NBT reduction was estimated by monitoring the change in absorbance at $560 \mathrm{~nm}$. The amount of enzyme extract that produced $50 \%$ inhibition of NBT reduction was considered as 1 unit (U) of SOD activity.

The catalase (CAT; EC 1.11.1.6) activity was estimated by Fan et al. (2014) method with some modifications. Activity was measured in terms of the degradation of hydrogen peroxide. The reaction mixture contained $1.9 \mathrm{~cm}^{3}$ of phosphate buffer $(50 \mathrm{mM}, \mathrm{pH} 7.4), 1 \mathrm{~cm}^{3}$ of $45 \mathrm{mM} \mathrm{H}_{2} \mathrm{O}_{2}$, and $0.1 \mathrm{~cm}^{3}$ of enzyme extract. Activity was measured by the decrease in absorbance at $240 \mathrm{~nm}$ at 1-min intervals for $3 \mathrm{~min}$. A unit of CAT activity was defined as the absorbance change of 1 unit per minute.

The peroxidase (POD; EC 1.11.1.7) activity was measured by the method described by Fan et al. (2014). The reaction mixture contained $0.05 \mathrm{~cm}^{3}$ of crude enzyme solution, $1 \mathrm{~cm}^{3}$ of guaiacol $(0.25 \%$, dissolved in $50 \%$ ethanol), $1.85 \mathrm{~cm}^{3}$ of acetic acid buffer ( $\mathrm{pH} \mathrm{5.0),} \mathrm{and}$ $0.1 \mathrm{~cm}^{3}$ of $0.75 \%(\mathrm{v} / \mathrm{v}) \mathrm{H}_{2} \mathrm{O}_{2}$. Absorbance at $460 \mathrm{~nm}$ at 1-min intervals was measured for $3 \mathrm{~min}$. A unit of POD activity was defined as the absorbance change of 1 unit per minute.

Chlorophyll $a$ fluorescence transient (OJIP) curves: The shape of the OJIP curve is very sensitive to environmental stresses. The OJIP transients of cells after salt stress treatments were measured using pulse-amplitude modulation (PAM) fluorimeter (PAM 2500, Heinz Walz, Effeltrich, Germany) with a high time resolution (10 $\mu \mathrm{s})$. In this study, the leaves were kept in dark for 20 min before the measurements were started. The OJIP transients were triggered by a red radiation of $3000 \mu \mathrm{mol}$ (photons) $\mathrm{m}^{-2} \mathrm{~s}^{-1}$ by the PAM 2500 through an array of light-emitting diodes. The fluorescence was subsequently measured and digitized between $10 \mu \mathrm{s}$ and $300 \mathrm{~ms}$. The OJIP transients were analyzed by the JIP-test method described by Liu et al. (Liu et al. 2016).

Metabolite extraction and derivatization: Extraction and derivatization of metabolites from samples for gas chromatography - mass spectrometry (GC-MS) analysis were performed by using a modified method that was previously outlined by $\mathrm{Hu}$ et al. ( $\mathrm{Hu}$ et al. 2016). For each sample, about $0.3 \mathrm{~g}$ of fresh leaves were ground to a fine powder in liquid nitrogen, transferred into a centrifuge tube $\left(15 \mathrm{~cm}^{3}\right)$, and then extracted in $4.2 \mathrm{~cm}^{3}$ of $80 \%(\mathrm{v} / \mathrm{v})$ aqueous methanol under intensive oscillation $(200 \mathrm{~g})$ at $25^{\circ} \mathrm{C}$ for $2 \mathrm{~h}$. After extraction, $60 \mathrm{~mm}^{3}$ of ribitol solution $\left(2 \mathrm{mg} \mathrm{cm}^{-3}\right)$ as an internal standard was added and incubated in a metal bath at $70{ }^{\circ} \mathrm{C}$ for $15 \mathrm{~min}$. The tube was centrifuged at $12000 \mathrm{~g}$ and $20{ }^{\circ} \mathrm{C}$ for $5 \mathrm{~min}$, the supernatant was decanted to new $10-\mathrm{cm}^{3}$ tubes, and $4.5 \mathrm{~cm}^{3}$ of water and $2.25 \mathrm{~cm}^{3}$ of chloroform were added. The mixture was vortexed and centrifuged at $8000 \mathrm{~g}$ for $15 \mathrm{~min}$. The supernatant was the polar phase, which was collected for derivatization.

The polar phase supernatant $\left(400 \mathrm{~mm}^{3}\right)$ was transferred into $1.5 \mathrm{~cm}^{3}$ high-performance liquid chromatography (HPLC) vials and dried in a vacuum concentrator (Labconco Corporation, Kansas City, KS, USA) overnight. The dried residue was redissolved and derivatized under intensive oscillation $\left(200 \mathrm{~g}\right.$ ) at $37{ }^{\circ} \mathrm{C}$ (in $110 \mathrm{~mm}^{3}$ of $20 \mathrm{mg} \mathrm{cm}^{-3}$ methoxyamine hydrochloride in pyridine) for $2 \mathrm{~h}$ followed by a $2 \mathrm{~h}$ treatment at $37^{\circ} \mathrm{C}$ with $60 \mathrm{~mm}^{3}$ of N-methyl-Ntrimethylsilyl trifluoroacetamide (MSTFA).

Metabolite data processing and analysis: The metabolites were measured by using GC-MS (Agilent 7890A/5975C, Agilent Technologies, Palo Alto, CA, USA) system based on the method of Xie et al. (2014). The $1 \mathrm{~mm}^{3}$ of the derivatized extract was injected into a $D B-5 M S$ capillary $(30 \mathrm{~m} \times 0.25 \mathrm{~mm} \times 0.25 \mu \mathrm{m}$, Agilent $J \& W G C$ column $)$ (Xie et al. 2014). The GC temperature was programmed as follows: $70{ }^{\circ} \mathrm{C}$ for $5 \mathrm{~min}$ and then an increase by a $5^{\circ} \mathrm{C}$ per min rate to $300^{\circ} \mathrm{C}$ and hold for $10 \mathrm{~min}$. Subsequently, after $1 \mathrm{~min}$ of injection, the electron current was set at $70 \mathrm{eV}$, the injection temperature was adjusted to $280{ }^{\circ} \mathrm{C}$, and the oven temperature was ramped up to $290^{\circ} \mathrm{C}$. The ion source temperature was $230^{\circ} \mathrm{C}$. After the solvent delay time of $5 \mathrm{~min}$, the scanning speed was conducted at 0.6 scans s$^{-1}$ with a full scan mode (m/z 30/650).

The metabolites were identified by the application of the Agilent MSD Productivity Chemstation software and coupled with the commercially available compound libraries (NIST 11) (Gaithersburg, MD, USA). Relative quantification of the metabolites was determined according to the value of internal standard ribitol. The hierarchical clustering analysis (HCA) was done by using the MetaboAnalyst webpage (http://www.metaboanalyst.ca/ MetaboAnalyst/) (Xia et al. 2009). Finally, we calculated the log-transformed response ratio of each identified substance before statistical estimation.

Statistical analysis: The experiments in this study were repeated three times and the data shown are the means \pm SDs. The data were analyzed by one-way analysis of variance $(A N O V A)$ followed by the least significant difference test at $\alpha=0.05$ level using the statistical software SPSS 20.0. 


\section{Results}

Compared with the control, there was no obvious morphological change at $200 \mathrm{mM} \mathrm{NaCl}$, a few leaves dropped under $300 \mathrm{mM} \mathrm{NaCl}$. However, the leaves turned yellow and curly after treatment with 400 and $500 \mathrm{mM}$ $\mathrm{NaCl}$ (Fig. 1 Suppl.). Salt injury index showed no change at $200 \mathrm{mM} \mathrm{NaCl}$ and a considerable increase from 300 to $500 \mathrm{mM} \mathrm{NaCl}$ as compared to the control plants. (Fig. $1 A$ ). Moreover, leaf RWC decreased with an increase in the salinity which was especially significant at 300 to $500 \mathrm{mM}$ $\mathrm{NaCl}$ (Fig. 1B).

The content of MDA, a product of lipid peroxidation, and EL reflect the extent of damage in the cell membranes. In this study, MDA and EL showed no change in $200 \mathrm{mM}$ $\mathrm{NaCl}$ compared to the control, but gradually increased with increasing salt concentration. The highest MDA and EL values were reached at $500 \mathrm{mM} \mathrm{NaCl}$ but there was no significant difference between 400 and $500 \mathrm{mM} \mathrm{NaCl}$ (Fig. $1 C, D$ ).

As compared to the control plants, antioxidative activities showed no remarkable changes at $200 \mathrm{mM}$ $\mathrm{NaCl}$ (Fig. 2). The SOD activity also showed no change at $300 \mathrm{mM} \mathrm{NaCl}$ but significantly increased at 400 and especially at $500 \mathrm{mM} \mathrm{NaCl}$ (Fig. 2A). The POD activities similarly increased at 300 and $400 \mathrm{mM} \mathrm{NaCl}$ and further increased at $500 \mathrm{mM} \mathrm{NaCl}$ (Fig. 2B). The leaf CAT activities were significantly higher at 300 to $500 \mathrm{mM}$ $\mathrm{NaCl}$ compared with the control, but the changes were not significant among 300,400 , and $500 \mathrm{mM} \mathrm{NaCl}$ treatments (Fig. 2C).

There were no significant changes in the original fluorescence with increasing salinity, but the fluorescence yield at the J, I, and P phases (J-P curve) clearly changed. The J-P curve was higher in the 200 and $300 \mathrm{mM} \mathrm{NaCl}$ than in the control and the curve at $200 \mathrm{mM} \mathrm{NaCl}$ was higher than at $300 \mathrm{mM} \mathrm{NaCl}$. At 400 and especially $500 \mathrm{mM} \mathrm{NaCl}$, J-P curves were below the control (Fig. 3).

For the effects of salinity on electron transport at the acceptor side of photosystem (PS) II, $\varphi \mathrm{Po}, \Psi \mathrm{o}$, and $\varphi$ Eo were compared under different $\mathrm{NaCl}$ concentrations. We observed that $\varphi$ Po, $\Psi$ o, $\varphi$ Eo were unaffected up to $400 \mathrm{mM}$ $\mathrm{NaCl}$, but were significantly decreased at $500 \mathrm{mM} \mathrm{NaCl}$. For the effect of salinity stress on the energy flux (per reaction center, $\mathrm{RC}$ ), for electron transport (ET/RC), and dissipation (DIo/RC), there were no significant differences up to $400 \mathrm{mM} \mathrm{NaCl}$, but increased $\mathrm{DIo} / \mathrm{RC}$ and decreased $\mathrm{ETo} / \mathrm{RC}$ were observed at $500 \mathrm{mM} \mathrm{NaCl}$ (Table 1 Suppl.).

The effects of salinity stress on the number of phenomenological fluxes for trapping per cross-section $\left(\mathrm{TR}_{\mathrm{O}} / \mathrm{CS}_{\mathrm{O}}\right)$ and dissipation per cross-section $\left(\mathrm{DI}_{\mathrm{O}} / \mathrm{CS}_{\mathrm{O}}\right)$, were not significantly different up to $400 \mathrm{mM} \mathrm{NaCl}$, but increased the $\mathrm{DIo} / \mathrm{CS}_{\mathrm{O}}$ and decreased $\mathrm{TR}_{\mathrm{O}} / \mathrm{CS}_{\mathrm{O}}$ in $500 \mathrm{mM}$ $\mathrm{NaCl}$ concentration was observed. High salinity stress (500 mM NaCl) significantly affected the PS II behavior, as quantified by the performance index; $\mathrm{PI}_{\mathrm{ABS}}$ and $\mathrm{PI}_{\mathrm{CS}}$ were decreased by 70 and $67 \%$, respectively, in $500 \mathrm{mM}$ $\mathrm{NaCl}$ compared with the control (Table 1 Suppl.).

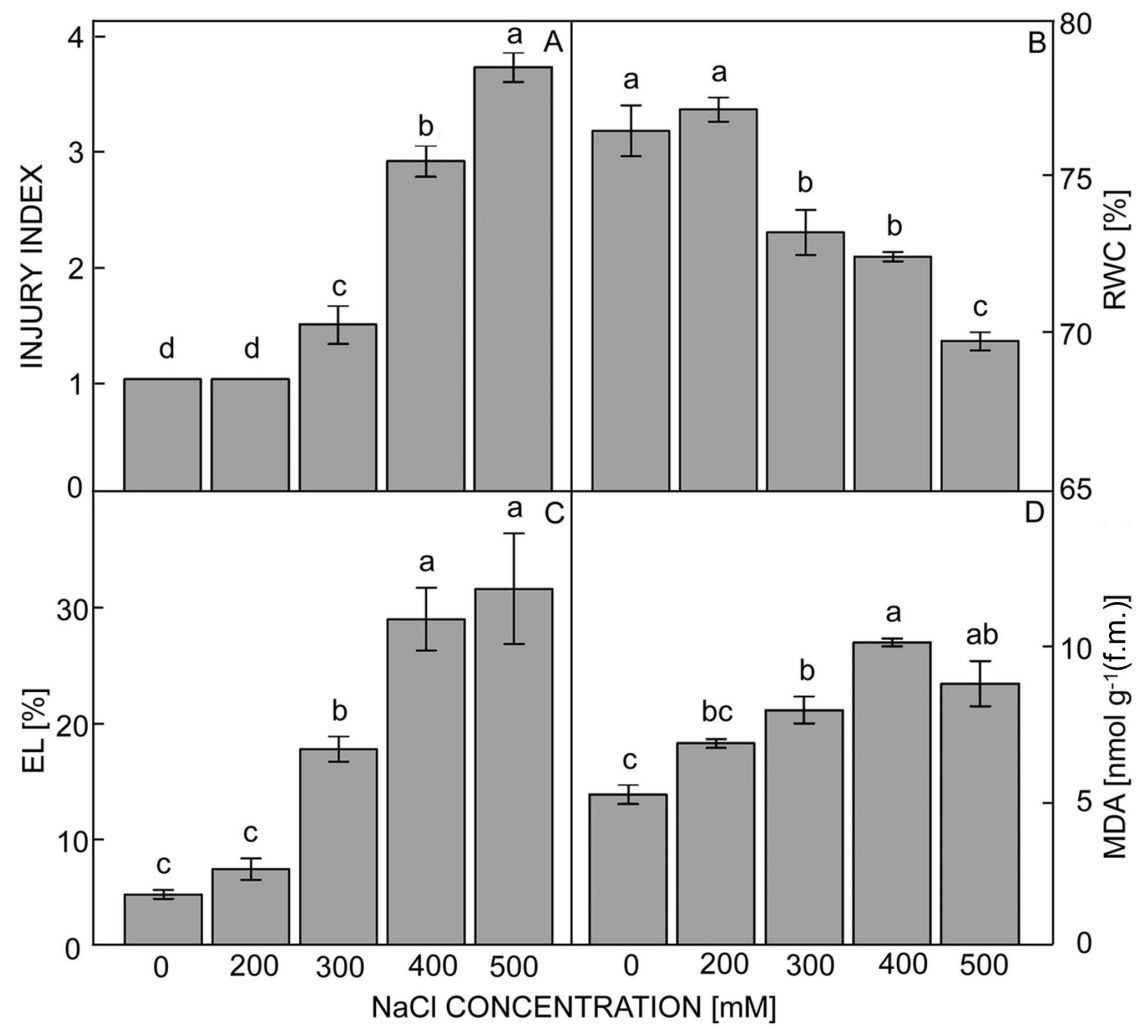

Fig. 1. The effects of salt stress on salt injury index $(A)$, relative water content (RWC, $B$ ), electrolyte leakage (EL, $C$ ), and malondehyldehide (MDA) content $(D)$ in Carex pumila leaves under different $\mathrm{NaCl}$ concentration $(0,200,300,400$, and $500 \mathrm{mM})$ for $60 \mathrm{~h}$. Means $\pm \mathrm{SDs}$, $n=3$, different letters indicate significant differences between treatments $(P<0.05)$ based on the least significant difference test. 




Fig. 2. Changes in superoxide dismutase (SOD, $A$ ), peroxidase (POD, $B$ ), and catalase (CAT, $C$ ) activities in the leaves of Carex pumila induced by different $\mathrm{NaCl}$ concentrations for $60 \mathrm{~h}$. Means \pm SDs, $n=3$, different letters indicate significant differences between treatments $(P<0.05)$ based on the least significant difference test.

Based on the analysis by GC-MS, a total of 39 kinds of differentially accumulated metabolites were identified and quantified, which included 9 amino acids, 16 organic acids, 9 sugars, 3 sugar alcohols, and 2 amines (Fig. 4).

The amount of most amino acids and their derivatives were higher in NaCl-treated plants than in the control group, and these were important products of amino acid metabolism and synthesis. The content of organic acids could be divided into two categories. The first category was increased under salt stress and these products were mostly produced by the TCA cycle. The second group was decreased under salt stress and these were products of fatty acid metabolism. The content of majority sugars and sugar alcohols was higher in salinity-treated plants and these products are mainly involved in galactose metabolism. The content of amines was decreased by salt stress and mainly involved in nitrogen metabolism (Table 2 Suppl.).

Additionally, 17 metabolites comprising eight amino acids, five sugars, two sugar alcohols, and two organic acids assigned to glycolysis, tricarboxylic acid (TCA) cycle, and oxidative pentose phosphate pathway were identified (Fig. 2 Suppl., Table 3 Suppl.).

\section{Discussion}

Halophytes adapt to the salt environment through regulation of physiology and metabolism (Flowers and Colmer 2015). In our study, we found that $C$. pumila can survive stably in the coastal sandy land, and revealed the possible salt tolerance mechanism of halophytes based on its physiological, photosynthetic, and metabolite responses under salt stress.

Halophytes can tolerate and complete their life cycle at salt concentrations of $200 \mathrm{mM} \mathrm{NaCl}$ (Flowers and Colmer 2015). In the present study, C. pumila was defined as an obligate halophyte which can survive in $2 \%$ (about $350 \mathrm{mM} \mathrm{NaCl}$ ) salinity, despite a decline in plant growth (Sykes and Wilson 1989). In this experiment, we observed that $300 \mathrm{mM} \mathrm{NaCl}$ induced no obvious morphological change, salt injury index gradually increased with an increase in salinity after $300 \mathrm{mM}$ treatment. Plant water status is highly sensitive to salinity and, therefore, a dominant factor in determining the plant responses to stress (Meng et al. 2017). Regulation of water balance measured by leaf RWC is considered to be one of the most important adaptation measures to salt stress (Noreen et al. 2010, Ahmad et al. 2012, Franzini et al. 2019). In this work, significant declines in RWC were observed at 400 and $500 \mathrm{mM} \mathrm{NaCl}$ which was consistent with previous reports (Hu et al. 2012, Liu et al. 2016, Bela et al. 2018). This result corresponded with the ability of $C$. pumila to survive at the measured $\mathrm{NaCl}$ concentration in the field investigation. The stress time of this treatment was only $60 \mathrm{~h}$, because we considered that $C$. pumila was mainly affected by the regular stress from seawater tides. In our continuous salt stress experiment, it was found that C. pumila showed obvious morphological (severe water loss in the leaves) changes under $300 \mathrm{mM}$ salt stress at about $100 \mathrm{~h}$. However, we still think that $C$. pumila could be a very good halophyte for the restoration of the coastal zone.

Membrane lipid peroxidation characterized by MDA content and EL has been often used as salt stress biomarkers (Ahmad et al. 2012, Hossain et al. 2019). In our study, both markers significantly increased under 300 to $500 \mathrm{mM} \mathrm{NaCl}$, but showed no significant change at $200 \mathrm{mM} \mathrm{NaCl}$. This result implied that under higher salinity $(300-500 \mathrm{mM} \mathrm{NaCl}), C$. pumila exhibited enhanced lipid peroxidation and oxidative damage. Such a pattern of MDA accumulation has already been observed in other halophytes such as Salicornia persica and S. europaea (Aghaleh et al. 2009).

It is well known that salinity increased accumulation 


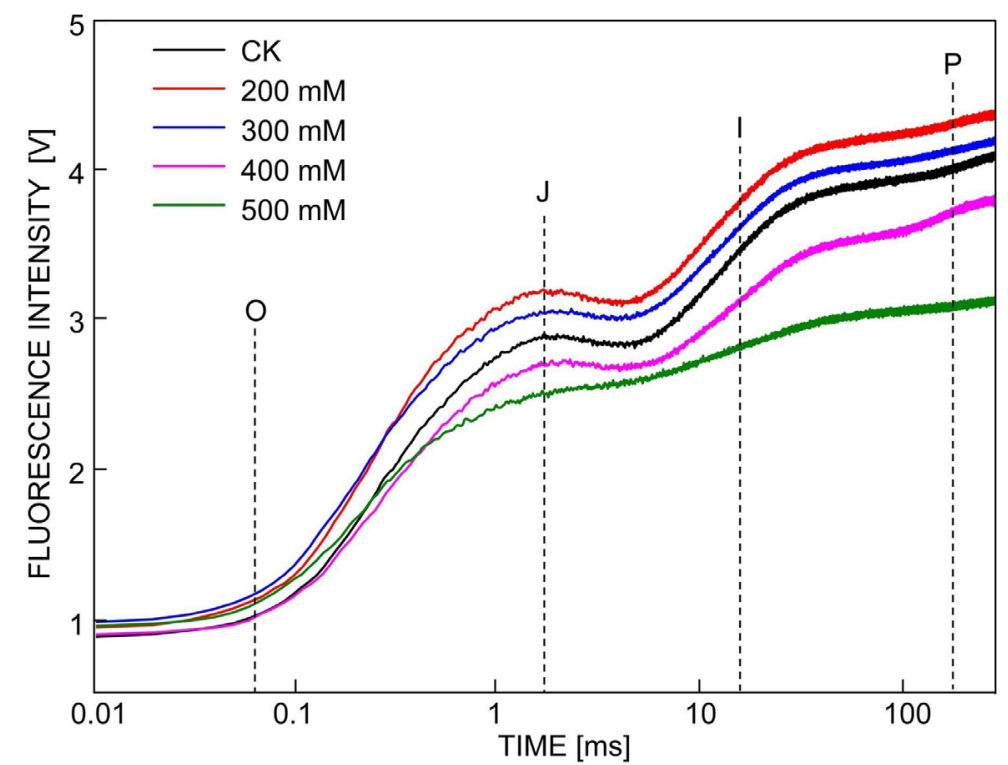

Fig. 3. Chlorophyll $a$ fluorescence induction transients (OJIP) in Carex pumila leaves after different salt treatments (0, 200, 300, 400, and $500 \mathrm{mM} \mathrm{NaCl}$ ) for $60 \mathrm{~h}$. The leaves were vacuum-infiltrated for $20 \mathrm{~min}$ in the dark. $\mathrm{O}$ - minimal reliable recorded fluorescence at $20 \mu \mathrm{s}, \mathrm{J}$ - fluorescence intensity at $2 \mathrm{~ms}$, I - fluorescence intensity at $30 \mathrm{~ms}, \mathrm{P}$ - maximal recorded fluorescence intensity.

of reactive oxygen species (ROS; Hernández et al. 2002, Hasanuzzaman et al. 2018), which can damage proteins, lipids, and nucleic acids (Foyer and Noctor 2005). The role of antioxidant enzymes (such as SOD, CAT, and POD) in salt-induced ROS scavenging has been demonstrated also in halophytes (Shabala 2013, 2016, Muchate et al. 2016, Rangani et al.). Among all the antioxidative enzymes, SOD is in the first line of defense converting superoxide to the less toxic $\mathrm{H}_{2} \mathrm{O}_{2}$ (Alscher et al. 2002, Bose et al. 2014). Enhanced $\mathrm{H}_{2} \mathrm{O}_{2}$ content is dismutased to $\mathrm{H}_{2} \mathrm{O}$ and $\mathrm{O}_{2}$ with the help of POD and CAT (Gao et al. 2020). An increase in the CAT activity has been shown as a measure of antioxidant defense in halophytes (Sekmen et al. 2012, Hossain et al. 2019). In our experiment, the SOD and POD activities gradually increased under 300 to $500 \mathrm{mM} \mathrm{NaCl}$ concentrations. It has been reported that exposure to salt stress in many plant species causes elevated activities of antioxidant enzymes, e,g, in Vigna radiata (Nazar et al. 2011), Chenopodium quinoa (Amjad et al. 2015), Oryza sativa (Lee et al. 2001), Triticum aestivum (Amjad et al. 2015), and Sesuvium portulacastrum (Muchate et al. 2016). However, in C. pumila, the CAT activity was enhanced significantly at $300 \mathrm{mM} \mathrm{NaCl}$ and the activity remained constant until $500 \mathrm{mM} \mathrm{NaCl}$, as observed in quinoa (Amjad et al. 2015), indicating that CAT had a high capacity for the decomposition of $\mathrm{H}_{2} \mathrm{O}_{2}$ generated by SOD. The tolerance to high salinity in C. pumila derives largely from the constitutively high antioxidative enzymatic activities and CAT may be of major significance in the salt adaptive mechanism.

Salinity affects plant growth as a result of alterations in many physiological processes including photosynthesis (Xia et al. 2009, Kalaji et al. 2011, Zhang et al. 2018). Chlorophyll $a$ fluorescence was regarded as a crucial tool for investigation of the photosystem II under abiotic stress conditions (Chen et al. 2013). In this study, the OJIP transient curve declined under high $\mathrm{NaCl}$ concentrations (400 and $500 \mathrm{mM}$ ). The $\mathrm{PI}_{\mathrm{ABS}}$ and $\mathrm{PI}_{\mathrm{CS}}$ as a sensitive indicator of photosynthetic performance based on light absorption (Bi et al. 2016, Hu et al. 2016), significantly decreased under high salinity, which suggested that salinity stress may inhibit electron transport at the donor side of PS II. Hagemyer (1999) and Perales-Vela et al. (2007) reported that to protect the plant growth from the extremely adverse environmental condition, excess excitation energy was transformed into thermal dissipation so as to maintain the energy balance between absorption and utilization. Thus the $\mathrm{PI}_{\mathrm{ABS}}$ and $\mathrm{PI}_{\mathrm{CS}}$ value also confirmed this finding. This result is consistent with the observation that PS II was highly susceptible to salinity stress (Corney et al. 2003, Xia et al. 2009). Simultaneously, the quantum yields of primary photochemistry $(\varphi \mathrm{Po})$, the quantum yield for electron transport $(\varphi \mathrm{Eo})$, and the efficiency per trapped excitation ( $\left.{ }_{0}\right)$ were also decreased by high salinity. These parameter can avail reliable information about electron transport activity at the acceptor side of PS II (Wang et al. 2011, Zhang et al. 2018). Furthermore, the specific energy fluxes $\left(\mathrm{DI}_{\mathrm{O}} / \mathrm{RC}\right.$ and $\left.\mathrm{ET}_{\mathrm{O}} / \mathrm{RC}\right)$ and phenomenological fluxes $\left(\mathrm{TR}_{\mathrm{O}} / \mathrm{CS}_{\mathrm{O}}\right.$ and $\left.\mathrm{DI}_{\mathrm{O}} / \mathrm{CS}_{\mathrm{O}}\right)$ of $C$. pumila leaves were markedly changed under high salinity (400 - $500 \mathrm{mM} \mathrm{NaCl}$ ), and those fluxes had a vital effect on the photosynthetic activity and also revealing that salt stress inhibited the energy absorption and dissipation in C. pumila to reduce the excessive energy production. However, in this study, the OJIP transient curve were higher under low $\mathrm{NaCl}$ concentration $(200$ - $300 \mathrm{mM})$ than in the control group, but all the JIP-tests had no significant changes. This result indicated that low salinity may have little effect on $C$. pumila in quantum efficiencies and the activity of PS II reaction center. Therefore, this may also be the result of continuous adaptation and evolution of C. pumila in the long-term salt environment. 


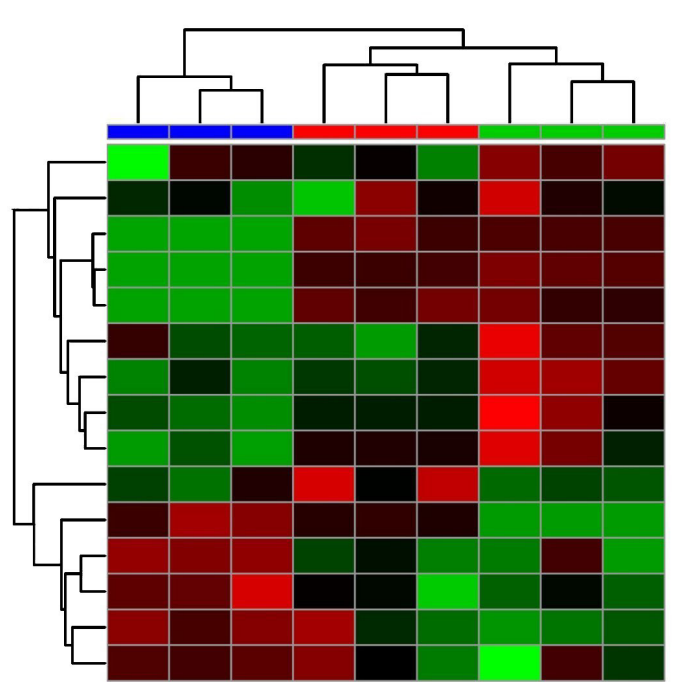

\section{$\sum_{\xi} \sum_{\varepsilon}$ \\ ㄴㅇㅇㅇㅇㅇ}

galactaric acid

succinic acid

benzoic acid

fumaric acid

glyceric acid

malonic acid

gluconic acid

glutaric acid

malic acid

hexadecanoic acid

propanoic acid

octadecanoic acid

phophoric acid

hexacosanoic acid

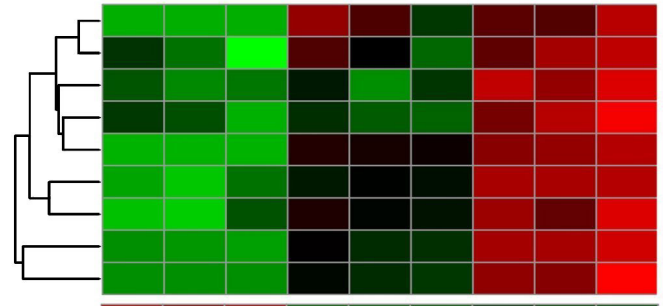

hydroxycarbamic acid

alanine

proline

aspartic acid

valine

serine

asparagine

glycine

threonine

isoleucine

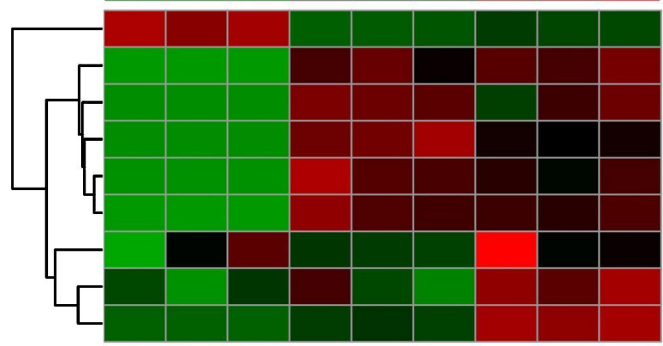

glucose

mannopyranoside

galactopyranose

glucopyranose

galactose

allose

sucrose

fructose

mannose

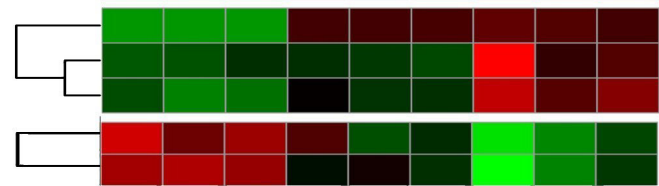

glycerol

galactinol

myo-inositol

ethanolamine

hydroxylamine
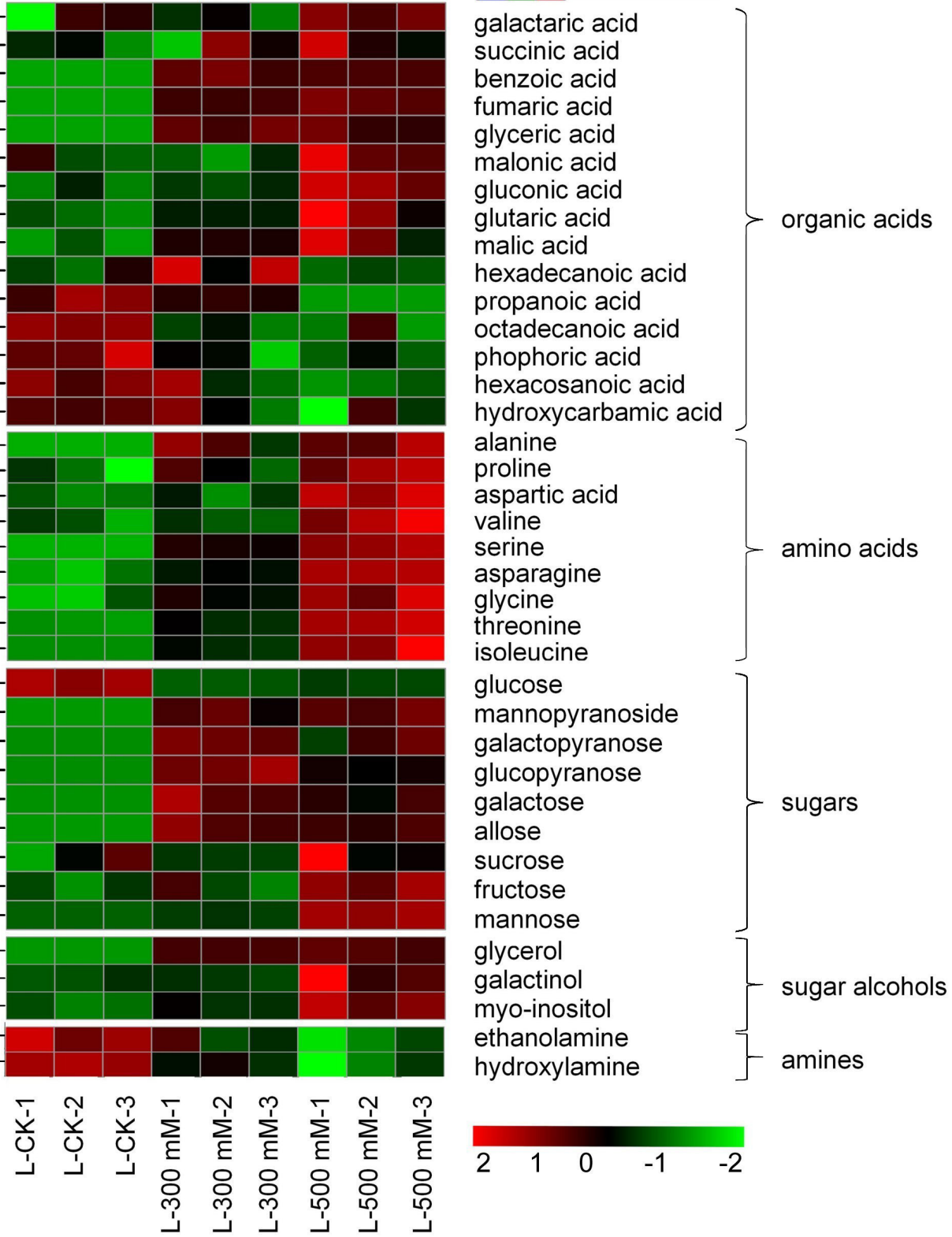

$\begin{array}{lllll}2 & 1 & 0 & -1 & -2\end{array}$

Fig. 4. The heat map of hierarchical cluster analysis of 39 metabolites in the leaves of Carex pumila in response to salt stress. The plants were treated with different $\mathrm{NaCl}$ concentrations $(0,300$, and $500 \mathrm{mM})$ for $60 \mathrm{~h}, \mathrm{CK}$ - control. Mean values were calculated from three independent experiments.

Metabolomics can perform a comprehensive analysis of a large number of metabolites, and is one of the fastest analytical methods for studying species under stress to determine products involved in metabolic responses (D'Amelia et al. 2018, Zhang et al. 2019). Plants respond to up and down regulation of multiple metabolites under salt stress, thereby preventing salt damage (Kumari et al. 2015, Ghatak et al. 2018). In this study, we found out that 39 metabolites were differentially expressed compared with control plants. Among these metabolites, there are amino acids, such as proline, alanine, arginine, serine, threonine, which play major roles in osmoregulation during salt stress (Slama et al. 2015). Sugars and sugar alcohols constantly accumulate under salt stress and our experiment suggested that sugars frequently accumulated in plants under salinity. Previous studies have reported that sugars played major roles as osmoprotectant, carbon storage, and scavenger of ROS accumulation (Kumari et al. 2015, Zhang et al. 2019, Li et al. 2020). Sugar alcohols interact with proteins, enzymes, and membranes for protection of cellular structures and in signaling (Valluru and Van den Ende 2011). Organic acids are often considered to 




Fig. 5. The proposed model of Carex pumila physiological, photosynthetic, and metabolic responses under salt stress. The left boxes represent the control group (CK) and the right boxes represent the salt stress (SS). Different alterations are marked with different colours; green represents a decrease and red an increase in given characteristics. For the abbreviations - see the text.

mainain the osmotic potential (Rybka and Nita 2015, Chen et al. 2019, Wang et al. 2019). Among them, fatty acids are important phase solvent, especially palmitic acid and hexacosanoic acid, participating in membrane lipid bilayer flow and signal transduction (Guo et al. 2017). The metabolites exhibited significantly higher content under salt stress conditions. These results indicated that the widespread effects of salt treatment on carbon metabolism, amino acid metabolism, nitrogen metabolism, and fatty acid metabolism might play some role in salt stress resistance in C. pumila (Table 3 Suppl.). In our study, it can be found that under salt stress, many metabolites involved in a variety of physiological metabolic pathways respond to the salt environment. Our research only provides an analysis from the metabolic pathway, and, in the future, it should be combined with the molecular research to jointly reveal its salt tolerance mechanism.

\section{Conclusions}

This study revealed adaptation mechanisms of the salttolerant halophyte $C$. pumila. It might be attributed to the different responses of $C$. pumila to salt stress, including alterations of osmotic adjustment, antioxidant system activity, PS II performance, and metabolic homeostasis (Fig. 5). This result provides a theoretical basis for the selection of plant material for breeding of salt-tolerant plants and for ecological restoration in coastal areas.

\section{References}

Aghaleh, M., Niknam, V., Ebrahimzadeh, H., Razavi, K.: Salt stress effects on growth, pigments, proteins and lipid peroxidation in Salicornia persica and S. europaea. - Biol.
Plant. 53: 243-248, 2009

Ahmad, P., Kumar, A., Ashraf, M., Akram, N.A.: Salt-induced changes in photosynthetic activity and oxidative defense system of three cultivars of mustard (Brassica juncea L.). Afr. J. Biotechnol. 11: 2694-2703, 2012.

Allakhverdiev, S.I., Sakamoto, A., Nishiyama, Y., Inaba, M., Murata, N.: Ionic and osmotic effects of $\mathrm{NaCl}$-induced inactivation of photosystems I and II in Synechococcus sp. Plant Physiol. 123: 1047-1056, 2000.

Alscher, R.G., Erturk, N., Heath, L.S.: Role of superoxide dismutases (SODs) in controlling oxidative stress in plants. J. exp. Bot. 53: 1331-1341, 2002.

Amjad, M., Akhtar, S.S., Yang, A., Akhtar, J., Jacobsen, S.E.: Antioxidative response of quinoa exposed to iso-osmotic, ionic and non-ionic salt stress. - J. Agron. Crop Sci. 201: 452460, 2015.

Bela, K., Riyazuddin, R., Horváth, E., Hurton, Á., Gallé, Á., Takács, Z., Zsigmond, L., Szabados, L., Tari, I., Csiszár, J.: Comprehensive analysis of antioxidant mechanisms in Arabidopsis glutathione peroxidase-like mutants under saltand osmotic stress reveals organ-specific significance of the AtGPXL's activities. - Environ. exp. Bot. 150: 127-140, 2018.

Bi, A., Fan, J., Hu, Z., Wang, G., Amombo, E., Fu, J., Hu, T.: Differential acclimation of enzymatic antioxidant metabolism and photosystem II photochemistry in tall fescue under drought and heat and the combined stresses. - Front. Plant Sci. 7: 453-453, 2016.

Bose, J., Rodrigo-Moreno, A., Shabala, S.: ROS homeostasis in halophytes in the context of salinity stress tolerance. - J. exp. Bot. 65: 1241-1257, 2014.

Burgess, R.E.: The life history strategy of Carex pumila Thunb. (Cyperaceae), a rhizomatous perennial pioneer species on the sand plains of the dune system of coastal Manawatu. Dissertations \& Theses, Massey University, Palmerston North 1984.

Chen, C., Liu, H., Wang, C., Liu, Z., Liu, X., Zou, L., Zhao, H., Yan, Y., Shi, J., Chen, S.: Metabolomics characterizes metabolic changes of Apocyni Veneti folium in response to salt stress. - Plant Physiol. Biochem. 144: 187-196, 2019.

Chen, K., Chen, L., Fan, J., Fu, J.: Alleviation of heat damage 
to photosystem II by nitric oxide in tall fescue. - Photosynth. Res. 1: 21-31, 2013.

Chen, T.H., Murata, N.: Glycinebetaine: an effective protectant against abiotic stress in plants. - Trends Plant Sci. 13: 499505, 2008.

Corney, H.J., Sasse, J.M., Ades, P.K.: Assessment of salt tolerance in eucalypts using chlorophyll fluorescence attributes. - New Forest. 26: 233-246, 2003.

D’Amelia, L., Dell'Aversana, E., Woodrow, P., Ciarmiello, L. F., Carillo, P.: Metabolomics for Crop Improvement against Salinity Stress. (Salinity Responses and Tolerance in Plants. Vol. 2.) - Springer-Verlag, Cham - Berlin - Heidelberg 2018.

Dahdouh-Guebas, F., Koedam, N.: Coastal vegetation and the Asian tsunami. - Science 311: 37-38, 2006.

Evelin, H., Kapoor, R., Giri, B.: Arbuscular mycorrhizal fungi in alleviation of salt stress: a review. - Ann. Bot. 104: 12631280, 2009.

Fan, J., Ren, J., Zhu, W., Amombo, E., Fu, J., Chen, L.: Antioxidant responses and gene expression in bermudagrass under cold stress. - J. amer. Soc. hort. Sci. 139: 699-705, 2014.

Feagin, R.A., Mukherjee, N., Shanker, K., Baird, A.H., Cinner, J., Kerr, A.M., Koedam, N., Sridhar, A., Arthur, R., Jayatissa, L.P.: Shelter from the storm? Use and misuse of coastal vegetation bioshields for managing natural disasters. Conserv, Lett. 3: 1-11, 2010.

Ferchichi, S., Hessini, K., Dell'Aversana, E., D’Amelia, L., Woodrow, P., Ciarmiello, L.F., Fuggi, A., Carillo, P.: Hordeum vulgare and Hordeum maritimum respond to extended salinity stress displaying different temporal accumulation pattern of metabolites. - Funct. Plant Biol. 45: 1096-1109, 2018.

Flowers, T.J., Colmer, T.D.: Plant salt tolerance: adaptations in halophytes. - Ann. Bot. 115: 327-331, 2015.

Foyer, C.H., Noctor, G.: Oxidant and antioxidant signalling in plants: a re-evaluation of the concept of oxidative stress in a physiological context. - Plant Cell Environ. 28: 1056-1071, 2005.

Franzini, V.I., Azcón, R., Ruiz-Lozano, J.M., Aroca, R.: Rhizobial symbiosis modifies root hydraulic properties in bean plants under non-stressed and salinity-stressed conditions. - Planta 249: 1207-1215, 2019.

Gao, Y.F., Liu, J.K., Yang, F.M., Zhang, G.Y., Wang, D., Zhang, L., Ou, Y.B., Yao, Y.A.: The WRKY transcription factor WRKY8 promotes resistance to pathogen infection and mediates drought and salt stress tolerance in Solanum lycopersicum. - Physiol. Plant. 168: 98-117, 2020.

Garg, N., Manchanda, G.: ROS generation in plants: boon or bane? - Plant Biosystem. 143: 81-96, 2009.

Ghatak, A., Chaturvedi, P., Weckwerth, W.: Metabolomics in plant stress physiology. - Adv. Biochem. Eng. Biotechnol. 164: 187-236, 2018.

Guo, R., Shi, L., Yan, C., Zhong, X., Gu, F., Liu, Q., Xia, X., $\mathrm{Li}, \mathrm{H}$.: Ionomic and metabolic responses to neutral salt or alkaline salt stresses in maize (Zea mays L.) seedlings. - BMC Plant Biol. 1: 1-13, 2017.

Hagemeyer, J. Ecophysiology of plant growth under heavy metal stress. - In: Hagemeyer, J.: Heavy Metal Stress in Plants. Pp. 201-222. Springer-Verlag, Berlin - Heidelberg 1999.

Hämmerli, A., Reusch, T.: Inbreeding depression influences genet size distribution in a marine angiosperm. - Mol. Ecol. 12: 619-629, 2003.

Hasanuzzaman, M., Oku, H., Nahar, K., Bhuyan, M.B., Al Mahmud, J., Baluska, F., Fujita, M.: Nitric oxide-induced salt stress tolerance in plants: ROS metabolism, signaling, and molecular interactions. - Plant Biotechnol. Rep. 12: 77-92, 2018.

Hernández, J.A., Almansa, M.S.: Short-term effects of salt stress on antioxidant systems and leaf water relations of pea leaves. - Physiol. Plant. 115: 251-257, 2002.

Hoagland, D.R., Arnon, D.I.: The water-culture method for growing plants without soil. - Circular Calif. Agr. Exp. Sta. 347: 1-39, 1950.

Hope-Simpson, R.B.J.F.: Downs and dunes: their plant life and its environment.by edward salisbury. - J. Ecol. 43: 311-315, 1955.

Hossain, M.S., Hasanuzzaman, M., Sohag, M.M.H., Bhuyan, M.B., Fujita, M.: Acetate-induced modulation of ascorbate: glutathione cycle and restriction of sodium accumulation in shoot confer salt tolerance in Lens culinaris Medik. - Physiol. mol. Biol. Plants 25: 443-455, 2019.

Hu, L., Hu, T., Zhang, X., Pang, H., Fu, J.: Exogenous glycine betaine ameliorates the adverse effect of salt stress on perennial ryegrass. - J. amer. Soc. hort. Sci. 137: 38-46, 2012.

Hu, Z., Fan, J., Xie, Y., Amombo, E., Liu, A., Gitau, M.M., Khaldun, A., Chen, L., Fu, J.: Comparative photosynthetic and metabolic analyses reveal mechanism of improved cold stress tolerance in bermudagrass by exogenous melatonin. Plant Physiol. Biochem. 100: 94-104, 2016.

Iwasato, M., Nagamatsu, D.: Plant species diversity and habitat conditions in a protected large coastal dune area of western Japan. - Lands Ecol. Eng. 14: 99-113, 2018.

Jenkins, S., Barrett-Lennard, E.G., Rengel, Z.: Impacts of waterlogging and salinity on puccinellia (Puccinellia ciliata) and tall wheatgrass (Thinopyrum ponticum): zonation on salt land with a shallow water-table, plant growth, and $\mathrm{Na}^{+}$and $\mathrm{K}^{+}$ concentrations in the leaves. - Plant Soil 329: 91-104, 2010.

Kalaji, H.M., Bosa, K., Kościelniak, J., Żuk-Gołaszewska, K.: Effects of salt stress on photosystem II efficiency and $\mathrm{CO}_{2}$ assimilation of two Syrian barley landraces. - Environ. exp. Bot. 73: 64-72, 2011.

Kumari, A., Das, P., Parida, A.K., Agarwal, P.K.: Proteomics, metabolomics, and ionomics perspectives of salinity tolerance in halophytes. - Front. Plant Sci. 6: 537-537, 2015.

Lee, D.H., Kim, Y.S., Lee, C.B.: The inductive responses of the antioxidant enzymes by salt stress in the rice (Oryza sativa L.). - J. Plant Physiol. 158: 737-745, 2001.

Li, Z., Cheng, B., Zeng, W., Zhang, X., Peng, Y.: Proteomic and metabolomic profilings reveal crucial function of $\gamma$-aminobutyric acid (GABA) on regulating ionic, water, and metabolic homeostasis in creeping bentgrass under salt stress. - J. Proteome Res. 19: 769-780, 2020.

Liu, A., Hu, Z., Bi, A., Fan, J., Gitau, M.M., Amombo, E., Chen, L., Fu, J.: Photosynthesis, antioxidant system and gene expression of bermudagrass in response to low temperature and salt stress. - Ecotoxicology 25: 1445-1457, 2016.

Lu, C., Vonshak, A.: Effects of salinity stress on photosystem II function in cyanobacterial Spirulina platensis cells. - Physiol. Plant. 114: 405-413, 2002.

Mansour, M.: Nitrogen containing compounds and adaptation of plants to salinity stress. - Biol. Plant. 43: 491-500, 2000.

Meng, R., Saade, S., Kurtek, S., Berger, B., Brien, C., Pillen, K., Tester, M., Sun, Y.: Growth curve registration for evaluating salinity tolerance in barley. - Plant Methods 13: 18-18, 2017.

Morton, M.J., Awlia, M., Al-Tamimi, N., Saade, S., Pailles, Y., Negrão, S., Tester, M. Salt stress under the scalpel-dissecting the genetics of salt tolerance. - Plant J. 97: 148-163, 2019.

Muchate, N.S., Nikalje, G.C., Rajurkar, N.S., Suprasanna, P., Nikam, T.D.: Physiological responses of the halophyte Sesuvium portulacastrum to salt stress and their relevance for saline soil bio-reclamation. - Flora 224: 96-105, 2016.

Nazar, R., Iqbal, N., Syeed, S., Khan, N.A.: Salicylic acid alleviates decreases in photosynthesis under salt stress by enhancing nitrogen and sulfur assimilation and antioxidant 
metabolism differentially in two mungbean cultivars. - J. Plant Physiol. 168: 807-815, 2011.

Noreen, Z., Ashraf, M., Akram, N. Salt-induced regulation of some key antioxidant enzymes and physio-biochemical phenomena in five diverse cultivars of turnip (Brassica rapa L.). - J. Agron. Crop Sci. 196: 273-285, 2010.

Parida, A.K., Das, A.B., Mohanty, P.: Defense potentials to $\mathrm{NaCl}$ in a mangrove, Bruguiera parviflora: differential changes of isoforms of some antioxidative enzymes. - J. Plant Physiol. 161: 531-542, 2004.

Perales-Vela, H.V., González-Moreno, S., Montes-Horcasitas, C., Cañizares-Villanueva, R.O.: Growth, photosynthetic and respiratory responses to sub-lethal copper concentrations in Scenedesmus incrassatulus (Chlorophyceae). - Chemosphere 67: 2274-2281, 2007.

Rangani, J., Parida, A.K., Panda, A., Kumari, A.: Coordinated changes in antioxidative enzymes protect the photosynthetic machinery from salinity induced oxidative damage and confer salt tolerance in an extreme halophyte Salvadora persica L. Front. Plant Sci. 7: 50-50, 2016.

Rodgers III, J.C., Murrah, A.W., Cooke, W.H.: The Impact of hurricane Katrina on the coastal vegetation of the Weeks Bay Reserve, Alabama from NDVI data. - Estuaries Coasts 32: 496-507, 2009.

Rozema, J., Van Manen, Y., Vugts, H., Leusink, A.: Airborne and soilborne salinity and the distribution of coastal and inland species of the genus Elytrigia. - Acta bot. neerl. 32: 447-456, 1983.

Rybka, K., Nita, Z.: Physiological requirements for wheat ideotypes in response to drought threat. - Acta Physiol. Plant. 37: 97-97, 2015.

Scandalios, J.G.: Oxygen stress and superoxide dismutases. Plant Physiol. 101: 7-12, 1993.

Sekmen, A.H., Turkan, I., Tanyolac, Z.O., Ozfidan, C., Dinc, A.: Different antioxidant defense responses to salt stress during germination and vegetative stages of endemic halophyte Gypsophila oblanceolata BARK. - Environ. exp. Bot. 77: 6376, 2012.

Shabala, S.: Learning from halophytes: physiological basis and strategies to improve abiotic stress tolerance in crops. - Ann. Bot. 112: 1209-1221, 2013.

Shahverdi M. A., Omidi H, Tabatabaei S. J.: Stevia (Stevia rebaudiana Bertoni) responses to $\mathrm{NaCl}$ stress: growth, photosynthetic pigments, diterpene glycosides and ion content in root and shoot. - J. Saudi Soc. agr. Sci. 18: 355-360, 2019.

Sivritepe, N., Erturk, U., Yerlikaya, C., Turkan, I., Bor, M., Ozdemir, F.: Response of the cherry rootstock to water stress induced in vitro. - Biol. Plant. 52: 573-576, 2008.

Slama, I., Abdelly, C., Bouchereau, A., Flowers, T., Savoure, A.: Diversity, distribution and roles of osmoprotective compounds accumulated in halophytes under abiotic stress. - Ann. Bot. 115: 433-447, 2015.

Stitt, M., Hurry, V.: A plant for all seasons: alterations in photosynthetic carbon metabolism during cold acclimation in Arabidopsis. - Curr. Opin. Plant Biol. 5: 199-206, 2002.

Sykes, M., Wilson, J.: The effect of salinity on the growth of some New Zealand sand dune species. - Acta Bot. Neerlandica 38: 173-182, 1989.

Valluru, R., Van den Ende, W.: Myo-inositol and beyondemerging networks under stress. - Plant Sci. 181: 387-400, 2011.

Wang, G., Chen, L., Hao, Z., Li, X., Liu, Y.: Effects of salinity stress on the photosynthesis of Wolffia arrhiza as probed by the OJIP test. - Fresenius environ. Bull. 20: 432-438, 2011.

Wang, Y., Zeng, X., Xu, Q., Mei, X., Yuan, H., Jiabu, D., Sang, Z., Nyima, T.: Metabolite profiling in two contrasting Tibetan hulless barley cultivars revealed the core salt-responsive metabolome and key salt-tolerance biomarkers. - AoB Plants 11: plz021, 2019.

Xia, J., Psychogios, N., Young, N., Wishart, D.S.: MetaboAnalyst: a web server for metabolomic data analysis and interpretation. - Nucl. Acids Res. 37: 652-660, 2009.

Xie, Y., Hu, L., Du, Z., Sun, X., Amombo, E., Fan, J., Fu, J.: Effects of cadmium exposure on growth and metabolic profile of bermudagrass [Cynodon dactylon (L.) Pers.]. - PLoS ONE 9: e115279, 2014.

Zhang, H., Li, X., Zhang, S., Yin, Z., Zhu, W., Li, J., Meng, L., Zhong, H., Xu, N., Wu, Y.: Rootstock alleviates salt stress in grafted mulberry seedlings: physiological and PS II function responses. - Front. Plant Sci. 9: 1806, 2018.

Zhang, Y., Li, D., Zhou, R., Wang, X., Dossa, K., Wang, L., Zhang, Y., Yu, J., Gong, H., Zhang, X.: Transcriptome and metabolome analyses of two contrasting sesame genotypes reveal the crucial biological pathways involved in rapid adaptive response to salt stress. - BMC Plant Biol. 19: 66-66, 2019.

Zheng, C., Jiang, D., Liu, F., Dai, T., Jing, Q., Cao, W.: Effects of salt and waterlogging stresses and their combination on leaf photosynthesis, chloroplast ATP synthesis, and antioxidant capacity in wheat. - Plant Sci. 176: 575-582, 2009.

Zhu, D., Hou, L., Xiao, P., Guo, Y., Deyholos, M.K., Liu, X.: VvWRKY30, a grape WRKY transcription factor, plays a positive regulatory role under salinity stress. - Plant Sci. 280: 132-142, 2019. 